\title{
Quality Maintenance of Production Equipment: A Case Study of Bendel Feeds and Mills, Ewu, Edo State
}

\author{
${ }^{1 *}$ Aigboje, O. E., ${ }^{2}$ Ugboya, A. P., \& ${ }^{3}$ Odiamenhi, A. M. \\ 1,2,3 Department of Industrial \& Production Engineering, Ambrose Alli University, Ekpoma, Nigeria \\ *Corresponding author's e-mail: Engr.eddyaigboje@gmail.com
}

\begin{abstract}
This paper analyses the quality maintenance in Bendel Feeds and Mills, Ewu, Edo State, with a view of designing a robust maintenance process and schedule to enhance production equipment in the company. The specific objectives were to determine the failure rate in the company production equipment, establish the appropriate maintenance process needed to reduce failure rate, investigate whether the current material handling methods and practices permit high maintenance turnover and to proffer useful suggestions and ideas on how to effectively maintain production equipment in the company. Data obtained were used to analyse the materials handling equipment failure rate, MTTR, MTBF, availability, failure mode and work station. The results showed that the failure rate is more in bucket elevator equipment than other materials handling equipment. It was observed that the plant organisational structure is area controlled instead of centre controlled organisation, which is one of the problems of the plant maintenance policy adopted by the company. Maintenance of materials handling equipment of the plant can be better achieved through modified planned preventive maintenance, condition base maintenance (predictive) and equipment inspection. This analysis will be of tremendous help to practicing maintenance engineering.
\end{abstract}

\begin{tabular}{l} 
Keywords \\
\hline Equipment failure \\
rate; \\
Equipment \\
inspection; \\
Maintenance cost; \\
Maintenance \\
process; \\
Materials \\
handling; \\
Preventive \\
maintenance.
\end{tabular}

Received 30 June 2019; Revised 10 August 2019; Accepted 15 August 2019;

Available online 30 August 2019.

Copyright ( 2019 The Authors. This is an open access article under the CC BY-NC-ND license (http://creativecommons.org/licenses/by-nc-nd/4.0/)

\section{Introduction}

Over the past few years, the manufacturing industries have engaged in profound changes within maintenance services. In particular, the adoption of preventive maintenance has led companies to take equipment operating conditions and industrial maintenance issues into serious account from the equipment design step. The purpose of this approach is to ensure maximum equipment quality, availability, reliability and safety, as well as to facilitate future maintenance interventions, on which production output partly depends (Mothes, 2018). Maintenance involves functional checks, servicing, repairing or replacing of necessary devices, equipment, machinery, building infrastructure and supporting utilities in industrial, business, governmental and residential installations. Over time, this has come to include multiple wordings that describe various cost-effective practices to keep equipment operational. These activities take place either before or after a failure (EFNMS, 2016).

Citation: Agboje, O. E., Ugboya, A. P., \& Odiamenhi, A. M. (2019). Quality Maintenance of Production Equipment: A Case Study of Bendel Feeds and Mills, Ewu, Edo State. Journal of Advances in Science and Engineering, 2(2): 1-7. DOI: https://doi.org/10.37121/jase.v2i2.54 
However, manufacturing is an important activity that promotes economic growth and development. Libanio (2006) through the use of Kaldor's first law defined manufacturing sector as the engine of growth of the economy. Manufacturing sector refers to those industries, which are involved in the manufacturing and processing of items and indulge in either creation of new commodities or in value addition (Adebayo, 2011). To Dickson (2010), manufacturing sector accounts for a significant share of the industrial sector in developed countries. The final products can either serve as finished goods for sale to customers or as intermediate goods used in the production process. Manufacturing sector according to Loto (2012) refers to an avenue for increasing productivity in relation to import replacement and export expansion, creating foreign exchange earning capacity, raising employment and per capita income, which causes unrepeatable consumption pattern. Mbelede (2012) opined that manufacturing sector is involved in the process of adding value to raw materials by turning them into product. Thus, manufacturing industries is the key variable in an economy and motivates conversion of raw material into finished goods. According to Charles (2012), manufacturing industries creates employment, which helps to boost agriculture and diversify the economy on the process of helping the nation to increase its foreign exchange earnings. Nations that export manufactured products tend to generate higher marginal GDP growth, which supports higher incomes and marginal tax revenue needed to fund the quality of life initiatives such as health care and infrastructure in the economy. The field is an important source for engineering job opportunities. Among developed countries, it is an important source of well-paying jobs for the middle class to facilitate greater social mobility for successive generations on the economy. Manufacturing sector plays a catalytic role in a modern economy and has many benefits crucial for economic transformation.

A failure can be sudden, gradual, partial, intermittent, or complete (Barnett \& Jerney, 1996). Carter (1996) proposes a failure nomenclature with six types, as: over-critical failures, involving safety; critical failures, item unserviceable; major failures, reduced usefulness; minor failures, marginally reduced usefulness; incidental failures, do not reduce usefulness; and non-relevant failures, do not matter. In classical maintenance, the definition of failure is the termination of the ability of an item to perform its required function (CEN/TC319: 1998). According to Jones (1995), degradation of system operation can be monitored, and certain events that were previously categorised as failures can be avoided by scheduled intervention to repair worn components. Thus, preventive maintenance can also be seen as repair of potential failures. A failure can also be classified in connection with source and cause (Vucinic, 1994), type/mode (Smith, 1988), mechanism (Barnett \& Jerney, 1996) and site (Lee et al., 1998). In accordance with maintenance standards BS4778 and BS3811, the different states of an item are classified as shown in Figure 1.

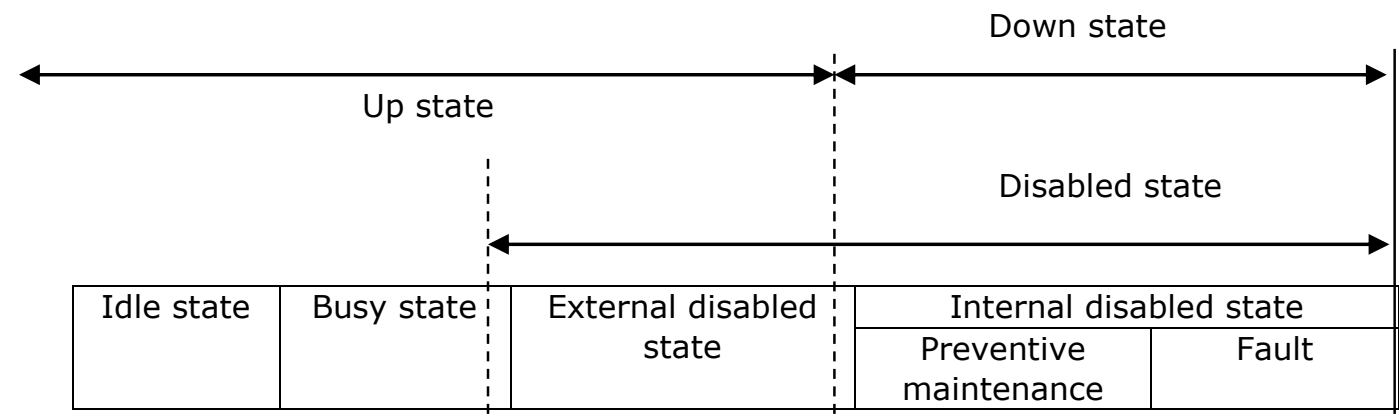

Figure 1. Classification of item states in the maintenance standards 
Notice that the time for preventive maintenance is viewed as an internal disabled state and included in the down state. The availability of an item is defined as the ability to be in a state to perform a required function under given conditions at a given instant of time or over a given time interval, assuming that the required external resources are provided.

Technical Failures (TF) can be referred to as a production disturbances and the measurement of such failure as the MTBF (mean time between failures). However, in automated manufacturing systems technical failure can be very short and frequent. From a maintenance perspective, technical failures often have been in focus for a stand-alone machine or a single item with simple failure causes which often have been treated as either is it functions or it does not. From a production point of view, in an efficiency perspective, humans and their erroneous actions have been the source for investigations as the limiting factor. In the quality area, deviation of product quality has been the focus of attention. In the ISO 9000 standard the term nonconformity is used. In ergonomics, beside human erroneous actions, the working conditions have been an emphasised subject. When it comes to safety, TF is treated as risks, and accidents are the focus for investigations. However, the problem with what is a technical failure or not can easily be overlooked. What is classified as a TF affects how it is handled as there are many definitions of TF in use e.g. disturbances/disruptions/failures/errors/defects/losses/waste, viewed from different perspectives in different areas and with different factors (Kuivanen, 1996).

The objective of this study is to analyse quality maintenance in Bendel Feeds and Mills, with a view of designing a robust maintenance process and schedule to enhance production equipment in the company. The specific objectives are to: determine the failure rate in the company production equipment; establish the appropriate maintenance process needed to reduce failure rate; investigate whether the current material handling methods and practices permit high maintenance turnover; and to proffer useful suggestions that will effectively maintain production equipment in the company.

\section{Methods}

\subsection{General Maintenance of Materials Handling Equipment}

A good maintenance program involves thorough general housekeeping, periodic, adequate lubrication, and timely adjustment. The preventive maintenance of different categories of materials handling equipment are discussed as follow:

Bucket elevator and conveyor belt. The preventive maintenance program should include general inspection of the followings: bucket for possible damage or loose bolt; adjustable throat plate for adjustment to the rubber lip or adjustable take ups for proper tension; and other items to be routinely inspected.

Elevator belt (in belt type). Check for wear at the edges of the belting, which would indicate that the belt is not tracking correctly and is contracting the side of the casing. Other procedures are as follow: (a) check for evidence of stretching, Some stretching is normal, and must be periodically compensated for by re splicing the belt and running the take ups back to the highest (or lowest if they are top take ups) position; (b) check for tearing, missing elevator bolts or bolt heads pulling through the belting; (c) loose bucket threat plate wiper improperly adjusted and contracting buckets, trash materials or tools present inside the Elevator; and (d) belt acquirement due to elevator and / shafts being out of plumb.

Elevation chain (in chain type). Check: (a) side bars, Side bars inner faces should be checked for wear. This is an indication of misalignment; (b) for missing cotter, missing cotter permit pin back off; (c) for insecure pin, loose or unseated pin are in danger signals and could lead to sudden and unexpected shutdown; (d) for excess materials build-up excess materials building up in chaining and attachments and rough operation, result accelerated wears; (e) for

$$
\text { IS S : } 2636-607 \times \quad 3 \text { |Page }
$$


rounded parts indicating wears; and (f) shockers for wears, sockets may show evidence of cupping or other wear marks.

Bearings. For the bearings, check operating temperature, sign of wear (noise) and lubrication.

\subsection{Trouble shooting of the Elevator Safety}

The followings safety of elevator must be observed when installing and after installation of the elevator:

(a) The safety labels and signs affixed to the equipment to warn of danger to persons and of possible equipment damage. These signs must never be removed, tampered with. Painted over or obscured in any way. If labels are damaged or become urea table, replacements tables are available from inter systems. A continuing program must be instituted by user to instruct all personnel in safe operating and maintenance procedure are to insure that all device, guards and covers are intact and operational and that all safety signs are legible.

(b) Removed accumulated dirt from the motor, reducer housings and bearing.

(c) Motors depend upon unobstructed airflow over their housing for effective cooling.

(d) Reducer's gears cases must be free of dirt for effective heat reduction. Most reducers have pressure vent to permit escape of vapours, which may, build up internally. If dirt blocks a vent, internal pressure can rupture seals. Leaking lubricant with contaminate the product being handle by the elevator and reducers failure and subsequent equipment downtime will definitely result if the leak is not discovered in time and repairs made. Original equipment manufacturers will refuse to honour warranties if a motors or reducer fails because dirt accumulation leads to overheating or lubricant failure.

(e) While cleaning the reducer, cheeks the reducer' lubricant level and condition. If the level is low, find and correct the leak. If the lubricant is dirty or shows signs of overheating schedule is charge of lubricant as soon as possible.

(f) Listen carefully for noisy motor, reducer bearings, a rubbing belt. Any of these sounds can be for warning overheating and fire or explosion. Correct any problem discovered immediately

(g) Bearing overheating.

(h) Drives unit over-heating.

\subsection{Collection of Field Failure Data}

Production managers routinely record failure data for the systems they manage as these systems are used for their intended purposes and maintain them upon failure. Data was retrieved from Bendel feeds and flour mills production line and was used to analyse the equipment failure modes: time of failure, workstations failure rate $(\lambda)$, mean time to repair (MTTR), mean time before failure (MTBF) and availability; maintenance practicing and policies, and cost analysis of maintenance and the production line. It consists of five workstations in series, where each workstation contains one or more machines and each machine has several failure modes.

To take into account the exogenous failures affecting the entire line, a sixth pseudoworkstation called the "exogenous" was defined. The exogenous workstation has three pseudo machines, which correspond to the electric, water, and air corresponding to a failure in the supply of one of the three resources mentioned above. Failures at workstation 6 are very important because they affect the entire line. The most significant of these failures is the failure of the electric power supply that supplies the system with electricity. The following notation was used to distinguish the different levels of the production line: WS. $i$ refers to Workstation $i$ and F.i.j.k is the failure mode $k$ of machine $j$ of workstation $i$.
4 | Pag e
I S S N : $2636-607 x$ 


\subsection{Analysis of the Equipment Failure Rate ( $\lambda$ ), MTBF, MTTR and Availability}

From the data collected, the number of time the bucket elevators, conveyors and forklift fails in a month and repair are listed as follow:

\section{Bucket elevator}

Number of time failed in a month $=10$ times

Repair time $=3$ days $=72 \mathrm{hrs}$

\section{Conveyor}

Number of time failed in a month $=12$ times

Repair time $\quad=1 \mathrm{hr}$

Forklift

Number of time failed in a month $=14$ times

Repair time $=56 \mathrm{mins}$

But failure rate can thus be regarded as the percentage of components working at the time $t$ and has the dimension of $1 / t$. Hence,
Failure rate $(\lambda)$
$=\frac{1}{t} \times 10^{-6} \mathrm{hr}$
MTBF
$=1 / \lambda$

The proportion of time during which the equipment is available for use is

Availability $\quad=\quad \frac{M T B F}{M T B F+M T T R}$

\section{Result and Discussion}

The workstations and machines of the company production line are shown in Table 1.

Table 1. Workstations and Machines of Bendel Feeds and Flour mills production line

\begin{tabular}{|c|c|}
\hline Workstations & Machines \\
\hline WS. 1 intake pit & $\begin{array}{c}\text { M.1.2 (2) } \\
\text { Elevator r-tipping device } \\
\text { (2mins) }\end{array}$ \\
\hline $\begin{array}{l}\text { WS.2 } \\
\text { Cleaning }\end{array}$ & $\begin{array}{cc}\text { M.2.1 (20) } & \text { M.2. }(15) \\
\text { Cleaning machine } & \text { Conveyor machine } \\
(30 \mathrm{~min}) & (2 \mathrm{mins}) \\
\end{array}$ \\
\hline $\begin{array}{l}\text { W.S.3 } \\
\text { Remover of metallic } \\
\text { particles }\end{array}$ & $\begin{array}{c}\text { M.3.1 (27) } \\
\text { Magnetic machine }\end{array}$ \\
\hline $\begin{array}{c}\text { W.S.4 } \\
\text { Weighing }\end{array}$ & $\begin{array}{l}\text { M.4.1 (10) } \\
\text { Weighing machine } \\
\quad(8 \text { mins })\end{array}$ \\
\hline $\begin{array}{l}\text { W.S. } 5 \\
\text { Storage }\end{array}$ & $\begin{array}{l}\text { M.5.1 (12) } \\
\text { Silo } \\
\text { (3mins) } \\
\end{array}$ \\
\hline $\begin{array}{c}\text { W.S.6 } \\
\text { Exogenous }\end{array}$ & $\begin{array}{l}\text { M.6.1 (1) } \\
\text { Electric power }\end{array}$ \\
\hline
\end{tabular}

The number of recorded failure modes at each machine is indicated inside a parenthesis next to the machine code. Also, the processing time per machine or workstation level is indicated inside a parenthesis below the machine or workstation name. Table 2 shows the materials handling equipment failure rate $(\lambda)$, MTBF, MTTR and availability 
Table 2. Materials handling equipment $\lambda$, MTBF, MTTR and Availability

\begin{tabular}{|c|c|c|c|c|}
\hline Machine & $\begin{array}{c}\text { Failure rate, } \boldsymbol{\lambda} \\
\mathbf{( 1 / h r )}\end{array}$ & MTBF, 1/ $\boldsymbol{\lambda}$ (hr) & $\begin{array}{c}\text { MTTR } \\
(\mathbf{h r})\end{array}$ & Availability \\
\hline Bucked elevator & $10 \times 10^{-7}$ & $10 \times 10^{5}$ & 72 & 0.999 \\
\hline Conveyor & $8.3 \times 10^{-7}$ & $12.05 \times 10^{5}$ & 1 & 0.9994 \\
\hline Forklift & $7.1 \times 10^{-7}$ & $14.01 \times 10^{5}$ & 0.933 & 0.999933 \\
\hline
\end{tabular}

From Table 2, the materials handling equipment in the mill indicates that failure rate is higher in bucket elevator than the other materials handling equipment. The MTTR for bucket elevator shows that as much as 72 hours is needed to repair it, which is the reason for the higher failure rate experienced in the bucket elevator. A well balanced maintenance program (or annual maintenance schedule) prepared by a maintenance engineer will outline the following; routine work, major overhaul and renewals. It also allocates downtime which is measure in hours. Downtime is a period where equipment is out of service due to maintenance. It serves as a basis for calculating maintenance cost. The result showed that the failure rate is more in bucket elevator equipment than other materials handling equipment.

\section{Conclusion}

Maintenance is an integral part of production process embracing repair, overhaul, inspection, rebuilding, alteration and the supply of spare parts, accessories, raw materials or parts from the time of receiving to the time of shipping the manufactured products. Analysed result showed that the failure rate of the plant materials handling equipment is higher in the bucket elevator than other materials handling equipment. It also showed that regular maintenance was needed. Results further showed that the plant organizational structure is area maintenance organization instead of centre controlled organisation. It was clear from the analysis of result that for quality maintenance of production equipment in Bendel Feeds and Mills, a robust maintenance process and schedule must be in place to reduce the high failure rate constantly experienced in the material handling equipment during production process and most importantly increase the company products turnover, for more profit. Also, for effective equipment maintenance of the plant and minimal failure in production equipment, proper condition monitoring should be adopted in the plant maintenance culture. It was also observed from analysis of result that preventive maintenance should be encouraged.

For materials handling equipment of the plant to function efficiently and effectively, it is recommended that:

(a) Materials handling equipment should not be used to lift or convey loads greater than their specified capacities.

(b) Users of materials handling equipment should engage the services of skilled and well-qualified personnel to service and maintain their equipment.

(c) A well planned preventive maintenance should be strictly followed.

(d) Defects detected during maintenance inspection should be eliminated instantly.

(e) Genuine spare parts should be used to replace worn-out or broken ones.

(f) Correct grades of lubricants should be used.

(g) Correct safety norms and procedure must be followed when operating and servicing of materials handling equipment.

\section{Conflict of Interests}

The authors declare that there is no conflict of interests regarding the publication of this paper. 


\section{References}

Adebayo, R. I. (2011). Zakat and Poverty Alleviation: A lesson for the Fiscal Policy Makers in Nigeria. Journal of Islamic Economics, Banking and Finance, 7(4): 26-41.

Barnelt, D. J.; \& Jerney, B. W. (1996). Reliability: if implication in production system OMEGA the int. Journal of management Science, 433-440.

Carter, A. D. S. (1996). Mechanical Reliability New York: John Wiley and Sons, Inc. $2^{\text {nd ED }}$.

CEN/TC319 (1998). Maintenance terminology (Draft), European Committee for standardization.

Charles, A. N. B. (2012). Investigating the Performance of Monetary Policy on manufacturing Sector in Nigeria. Arabian Journal of Business and Management Review, 2(1): 12-25.

EFNMS (European Federation of National Maintenance Societies), (2016). EFNMS.org. (Retrieved: 5 August, 2016).

Jones, R. B. (1995). Risk- based Management a reliability- cantered approval. Austion, TexA, Guff Publishing Company.

Kuivanen, R. (1996). Disturbance control in flexible manufacturing. International Journal of Human Factor in Engineering, 6(1): 41-56.

Lee, S. B.; Katz, A.; \& Hillman, C. (1998). Getting the Quality and Reliability Terminology Straight. IEEE Transaction on Components, Packaging, and Manufacturing Technology, 21(3): 521-523.

Libanio, G. (2006). Manufacturing industry and Economic Growth in Latin America: A Kaldorian Approach. CEDEPLAR, Brazil: Federal University of Minas Gerais, Brazil.

Loto, M. A. (2012). Global Economic Downturn and the Manufacturing Sector performance in the Nigerian Economy. Journal of Emerging Trends in Economics and Management Sciences, 3(1): 38-45.

Mbelede, C. (2012). Cost Engineering in the Manufacturing Sector of the Economy of Nigeria. Paper presented at the 3rd Annual Technical Conference of Institute of Appraisers and Cost Engineering, Abuja, Nigeria.

Mothes, D. (2018). Maintenance 4.0, How to improve manufacturing processes, http://www.mobility-work.com//case-study-improve-manufacturing-processes-main (Retrieved: 5 August, 2019)

Smith, D. J. (1988). Reliability and Maintainability in Perspective: Practical, contractual, commercial \& software Aspects. Hong Kong, Macmillan Education Ltd.

Vucinic, B. (1994). MA - CAD: Maintenance concept adjustment \& Design. Doctoral thesis. Faculty of Mechanical Engineering and Marine Technology, Delft, Technische University Delft. 